\title{
Influence of green's coconut fibers in the unsaturated behavior of compacted clayey soil
}

\author{
Luciana Regina Cajaseiras de Gusmão ${ }^{1, *}$, and José Fernando Thomé Jucá ${ }^{1}$ \\ ${ }^{1}$ Civil Engineering Postgraduation Department, Federal University of Pernambuco, Brazil
}

\begin{abstract}
The green coconut's shell is considered to be waste while it represents most of its volume and weight. The objective of this research was to analyze the influence of the addition of $1 \%$ (by weight) of green coconut's (Cocos nucifera) fibers in the unsaturated behavior of compacted mixtures of clayey soil, with fibers randomly distributed in the soil matrix. Both the pure soil and the mixture were submitted to filter paper tests according to Chandler and Gutierrez (1986) and Marinho (1994), in order to obtain their characteristic curves and verify their differences, using the relation suction-humidity proposed by Chandler, Crilly and Montgomery-Smith (1992) and van Genuchten's (1980) adjustment method, which was also used to estimate the unsaturated hydraulic conductivity and relative permeability to air and water as functions of the degree of saturation. The results revealed that the addition of fibers provided greater water percolation in the drying path, and greater air flow during wetting. This behavior is a reflection of the greater retention capacity provided by the fibers, which promotes a more gradual change in the degree of saturation, in relation to the 'pure soil', which is a very interesting characteristic for applications subject to large variations in humidity.
\end{abstract}

\section{Introduction}

Potentially usable productive resources treated as trash are a clear indication of waste. The search for sustainability requires viable proposals for the use of residues, transforming them into raw materials for new products, generating employment and income. The green coconut draws attention because its shell is considered the residue of a food product while it represents the majority of its volume and weight - normally it corresponds to more than $80 \%$ of its total weight (Rosa et al. 2001a [1]).

Responsible for almost $5 \%$ of the world's production of coconut, Brazil is the country with the 4th largest production of this input (Silveira \& Aragão 2016 [2]), where the Northeast accounts for about $75 \%$ of the national production and more than half of the consumption of green coconut (Ferreira Neto et al. 2002 [3]). In 2017 alone, the area planted or destined to harvest coconut in the national territory was almost 217 thousand hectares. Silva \& Jerônimo 2012 [4] call out to attention that the failure to use these generated residues represents, in practice, the elimination of infinite and renewable raw materials of great value, while they could be used to replace other products

\footnotetext{
*Corresponding author: lugusmao@gmail.com
}

whose extraction brings numerous ecological disadvantages, like peat and vermiculite, for example.

From the processing of this waste it is possible to obtain fibers and powder that will be raw materials in the manufacture of numerous other products, creating a productive chain oriented to sustainability (Martins et al. 2013 [5]). Between 1990 and 2009, Brazil went from 10th to 4th largest world producer of coconut fiber, with prospects for growth in productivity and market coverage (Martins \& Jesus Jr. 2011 [6]). Such production lacks a compatible consumer market. It is then necessary to enhance the applicability of this new raw material to stimulate sustainable consumption. Rosa et al. (2009) [7] state that the characteristics of coconut fiber make it suitable for reinforcing materials, especially in the preparation of composites, where it tends to reduce the density of the joint with good elongation potential and medium reinforcement capacity. It is important to notice that the binder capacity of lignin, present in large quantities, brings the possibility of improving the performance of the fiber-matrix interaction, as well as the action of heat in the formation of the composite

Geotechnical works require specific characteristics, and sometimes the soils available in deposits close to the locations either do not have properties suitable for the desired purpose, or do not have enough volume to meet 
local demands, or represent a large amount for the acquisition of materials. The incorporation of materials of good performance and low cost for the formation of composites appears as a possibility of using coconut residue, to be analysed in terms of technical feasibility. Savastano Jr. \& Pimentel (2000) [8] point out that vegetable fibers are subject to dimensional variations due to the high water absorption capacity in the humidity variation. These authors, as well as Toledo Filho et al. (2003) [9], think that the mechanical performance of plant materials inserted in composites undergo changes over time, depending on exposure conditions.

\section{Revision}

Despite greater clay fractions (smaller particles) promoting a greater number of contacts between soil particles (Tamrakar et al. 2005 [10]), the suction effect prevails, having been considered one of the main parameters for describing both macro and micromechanical behavior of unsaturated soils (Tang et al. 2016 [11]).

Tang et al. 2016 [11] suggest that, in the vadose zone of the soil, the resistance parameters tend to decrease with the depth of the profile due to the predominant action of evaporation in the most superficial region, where there is an induction of a greater suction gradient. Using micropenetrometers, the authors realized that the maximum depth whose resistance was affected by the drying process corresponds to the interface of the unsaturated and saturated zones of the profile. With continuous drying, the unsaturated zone gradually expands to greater depths (Shokri et al. 2008 [12]). The drying process promotes natural improvement of the mechanical behavior of the soil due to the increase of the active suction, and in the clays it also promotes the contraction and restructuring of its microstructure, which results in a denser arrangement, which, in general, increases the resistance soil (Tang et al. 2016 [11]).

Fredlund, Rahardjo \& Fredlund (2012) [13] explain that generally for degrees of saturation below $85 \%$ the air tends to behave as a continuous phase, but above $90 \%$ the air becomes occluded and its flow starts to occur only through the diffusion process. It is worth mentioning that the distribution of air in the voids of the soil will depend on the degree of initial saturation and whether it is on a drying or wetting trajectory (Marinho 1994 [14]). Evaluating air permeability as a function of soil moisture content or degree of saturation, it is possible to determine the efficiency of gas retention over environmental conditions (Mariano 2008 [15]).

Maciel \& Jucá (2000) [16] found a sudden decay in the air flow from $80 \%$ saturation for sandy-clay soil (SC in the SUCS classification) tested in the drying path. For high plasticity clay (with $10 \%$ fraction $<2 \mu \mathrm{m}$ and $\mathrm{CH}$ by SUCS) tested in the drying cycle, Maciel (2003) [17] found permeability values almost constant for $\mathrm{S}<60 \%$, a slow decrease between $60 \%$ and $85 \%$, and a drastic decrease from $85 \%$ saturation.

Loiseau, Cui \& Delage (2002) [18] found a slow variation in the coefficient of permeability to air in a clay (with $55 \%$ of fraction $<2 \mu \mathrm{m}$ ) for a degree of saturation between $55 \%$ and $85 \%$, and a rapid decrease for $\mathrm{S}>85 \%$.
Mariano (2008) [15] found the first phase with $S<65 \%$, the second with $65 \%<\mathrm{S}<75 \%$ and the third, $\mathrm{S}>75 \%$ for sandy-clay and sandy-clay soils with low plasticity (SC and CL by SUCS classification, respectively) in the drying cycle.

Lopes (2011) [19] found a sudden drop in air permeability for saturation above $90 \%$ in two silty soils with low compressibility (both classified ML by SUCS) and also for two mixtures of soil with organic compost from a tree pruning composting unit in different proportions, both with characteristics of silty soils with high compressibility (MH by SUCS). All samples showed stable permeability values until saturation of approximately $35 \%$.

Thus, it has to be said that for lower degrees of saturation (in general, between 55\% and 65\%) the presence of water practically does not interfere in the soil's air permeability, and the variations would be directly related to the structure (flocculated or dispersed) and soil compaction density. The degree of saturation after which a sharp change in the rate of change of the air permeability coefficient is verified indicates the generalized air entry point (GAE), at which the passage of the continuous phase of the air to the discontinuous state occurs (and vice versa, depending on the humidity trajectory employed) (Maciel 2003 [17], Mariano 2008 [15]).

\section{Methodology}

The characteristic curves of the 'pure soil' and the 'soilfiber' mixture were determined using the filter paper test, carried out based on the guidelines of Chandler \& Gutierrez (1986) [20], and Marinho (1994) [14]. We sought to evaluate the influence of the addition of coconut fibers on the water retention of the studied soil, as well as to estimate the unsaturated hydraulic conductivity, the field capacity, the air entry point, and the residual and saturation moisture contents for both.

The samples were extracted from specimens compacted and molded according to the procedures [21] in the optimum humidity. With the aid of a knife and scissors, 16 metal rings with $40 \mathrm{~cm}^{2}$ in size and $2 \mathrm{~cm}$ high were set into the surface of the PCs, 8 from the 'pure soil' and 8 from the 'mixture'. Whatman No. 42 filter paper was used, half of the rings used to build the retention curves in the drying cycle, and the other half, in the wetting cycle, in order to verify the occurrence of hysteresis. For each variation of approximately $3 \%$ of the gravimetric humidity of the samples, filter papers were placed in direct contact with the contents of the rings, for the purpose of determining the matrix suction related to the amount of water present in each case.

The sample-paper sets were wrapped in layers of plasticfilm (PVC) and aluminium foil and kept in a polystyrene box for 7 days (equalization period). After this period, the filter papers of each sample were removed with the aid of a metallic clamp and immediately placed on a precision scale of $0.0001 \mathrm{~g}$ to determine the wet weight of the paper. Then, the papers were placed in capsules for drying in an oven at $100{ }^{\circ} \mathrm{C}$ for 24 hours. After 24 hours, the capsules were removed from the oven and placed in a desiccator with silica 
to then weigh the filter papers, again on a precision scale, to determine the dry weight of the filter paper.

These procedures were repeated until the samples reached gravimetric moisture content considered constant. The matrix suction corresponding to the different moisture content of the samples was calculated from the moisture content of the filter papers, using the Equations (1) and (2), proposed by Chandler, Crilly \& Montgomery-Smith (1992) [22], where $w_{p}$ is gravimetric humidity of the filter paper $(\%)$, and $\psi$ is the suction $(\mathrm{kPa})$.

$$
\begin{gathered}
\psi=10^{6.05-2.48 * \log \left(w_{p}\right)}, \text { for } w_{p}>47 \% \\
\psi=10^{4.84-0.0622 * w_{p}}, \text { for } w_{p} \leq 47 \%
\end{gathered}
$$

Water retention curves were plotted using matrix suction as abscissa and volumetric humidity as ordered. The relationship between gravimetric and volumetric humidity was obtained through the physical indices shown in Equations (3) and (4). For a better definition of the curves, the adjustments proposed by van Genuchten (1980) [23] were made, using the Equation (5), where $S$ is the degree of saturation $(\%) ; w$ is the gravimetric humidity obtained (\%); $d_{g}$ is the grain density $\left(\mathrm{g} / \mathrm{cm}^{3}\right) ; e$ is the voids index; $\theta$ is the volumetric humidity $(\%) ; \theta_{\text {res }}$ is the residual volumetric moisture content, obtained experimentally (\%); $\theta_{\text {sat }}$ is the volumetric saturation moisture content, obtained experimentally (\%); and $\alpha$ and $n$ are curve adjustment parameters.

$$
\begin{gathered}
S=\frac{w * d g}{e} \\
\theta=\frac{S * e}{1+e} \\
\theta=\theta r+\frac{(\theta s-\theta r)}{\left[1+\left(\alpha * \psi^{n}\right)^{m}\right]}, \text { where } m=1-\frac{1}{n}
\end{gathered}
$$

The adjustments of the retention curves were performed using the Excel software. From the experimental values of $\theta_{\text {res }}$ and $\theta_{\text {sat }}$, and an initial estimate of the parameters $\alpha$ and $n$ of the van Genuchten model [23], the square of the deviation between each experimental's volumetric moisture value and the respective model's volumetric moisture value, corresponding to the same active suction: ( $\theta_{\text {experimental }}$ $\left.\theta_{\text {model }}\right)^{2}$. From the sum of the squares of the deviations, the Equation (6) was used to calculate the coefficient of determination $\left(R^{2}\right)$ of the curve adjusted using the van Genuchten model [23] for the initially estimated values of $\alpha$ and $n$, in relation to the experimental values of volumetric humidity, where $R^{2}$ is the coefficient of determination, SQD is the sum of the squares of the deviations, $N$ is the number of experimental measurements of $\theta$, and $S^{2}$ is the variance of de values obtained experimentally.

$$
R^{2}=1-\frac{S Q D}{N * S^{2}}
$$

The values of the curve fitting parameters ( $\alpha$ and $n$ ) were optimized using iterative methods using the Excel software Solver tool. Thus, it was obtained the combinations of parameters that provided the estimated values of $\theta_{\text {model }}$ as closest as possible to the calculated values of $\theta_{\text {experimental, }}$ resulting in the least sum of the squares of the deviations for the data set, and, consequently, in the highest coefficient of determination of the van Genuchten's fit curve $\left(R^{2}\right)$.

From the adjusted retention curves, the values for the air entry point and the moisture content for the field capacity $\left(\theta_{c c}\right)$ were graphically obtained, defined as the maximum humidity that can be retained by a porous medium without generating percolation, which can be understood as corresponding to the suction of $33 \mathrm{kPa}$ for clay soils (Ottoni 2005 [24]).

The water relative unsaturated conductivity was determined from the van Genuchten model [23], according to the Equations (7) and (8), considering that the results obtained through this method have presenting satisfactory estimates for modeling water flow in soils. The soil's air relative permeability coefficient was calculated from the Equations (9) and (10), with the coefficient relative to water being the complementary value, calculated through the Equation (11) [23], where $k\left(S_{\theta}\right)$ is the hydraulic conductivity corresponding to $S_{\theta}(\mathrm{m} / \mathrm{s}) ; S_{\theta}$ is the degree of saturation corresponds to $\theta(\%) ; \theta$ is the volumetric moisture content for which you want to determine unsaturated hydraulic conductivity (\%); ksat is the saturated hydraulic conductivity $(\mathrm{m} / \mathrm{s}) ; m$ is the adjustment parameter calculated according to Equation (5) (depending on the distribution of pores in the soil); Kra is the soil's coefficient of relative air permeability (dimensionless); $S_{e}$ is the effective saturation $(\%) ; S$ is the degree of saturation (\%); $S_{r}$ is the degree of saturation in residual moisture (\%); and $K_{r w}$ is the soil's coefficient of relative water permeability (dimensionless).

$$
\begin{gathered}
k\left(S_{\theta}\right)=k_{s a t} * S_{\theta}{ }^{0.5} *\left[1-\left(1-S_{\theta} \frac{1}{m}\right)^{m}\right]^{2} \\
S_{\theta}=\frac{\theta-\theta r}{\theta s-\theta r} \\
K_{r a}=1-\left\{S_{e}{ }^{0.5} *\left[1-\left(1-S_{e} \frac{1}{m}\right)^{m}\right]^{2}\right\} \\
S_{e}=\frac{S-S r}{1-S r} \\
K_{r w}=S_{e}{ }^{0.5} *\left[1-\left(1-S_{e} \frac{1}{m}\right)^{m}\right]^{2}
\end{gathered}
$$

\section{Results}

\subsection{Water retention curve}

The Figure (1) presents the experimental data (points) obtained for water retention of the 'pure soil' and the 'soilfiber' mixture in terms of matrix suction and volumetric moisture in drying paths, and the Figure (2), in wetting paths, each with its respective adjustment curves. The adjustments were made using the parameter sets of the van Genuchten model [23] which resulted in higher determination coefficients $\left(R^{2}\right)$, presented in Table (1). It is noteworthy that the high determination coefficients obtained 
indicate more than $97 \%$ of the experimental data can be explained by this numerical model.

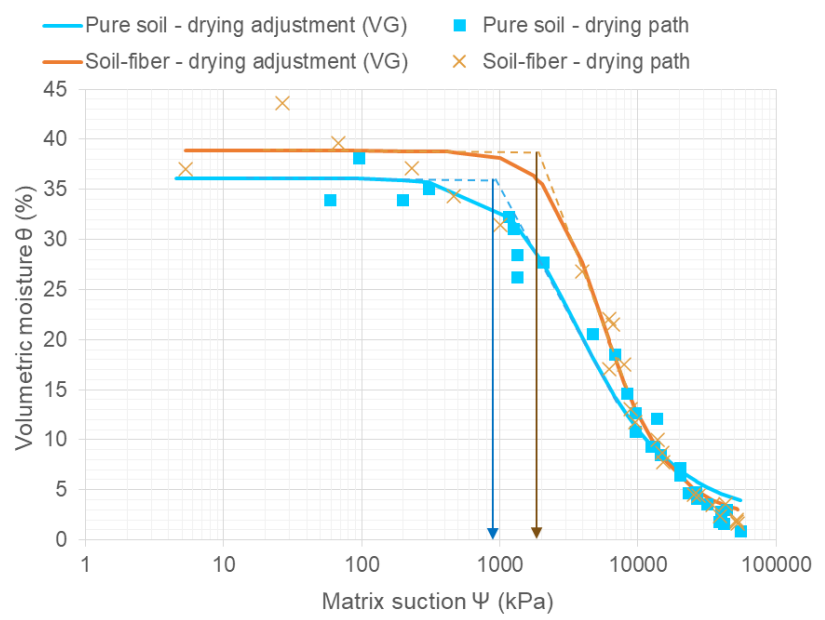

Fig. 1. Retention curves - drying paths

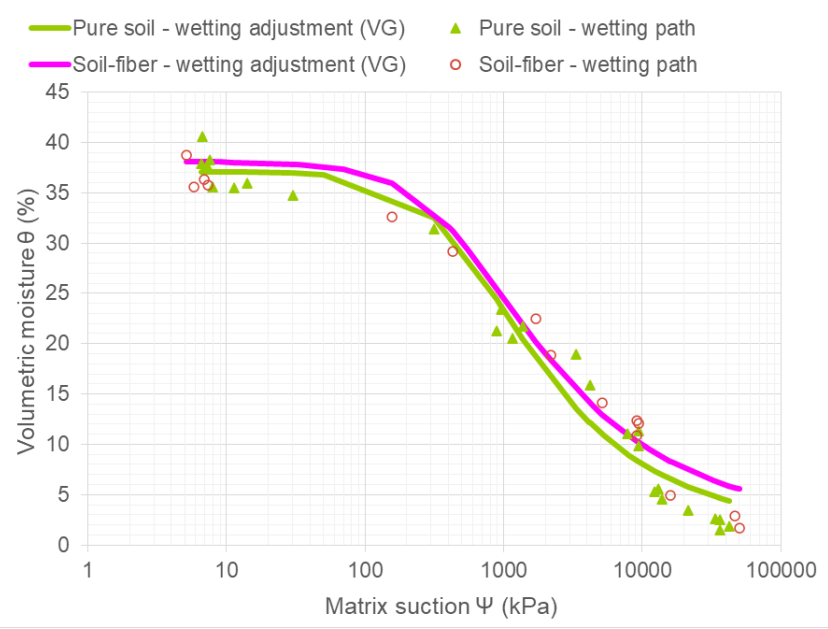

Fig. 2. Retention curves - wetting paths

Table 1. Parameters of the van Genuchten's equation and determination coefficients $\left(R^{2}\right)$ obtained in the adjustments of the water retention curves

\begin{tabular}{c|cccc}
\hline Curve & $\mathrm{a}$ & $\mathrm{n}$ & $\mathrm{m}$ & $\mathrm{R}^{2}$ \\
\hline Pure soil - drying & $4.46 \times 10^{-4}$ & 1.852 & 0.460 & 0.9722 \\
Pure soil - wetting & $1.95 \times 10^{-3}$ & 1.569 & 0.362 & 0.9726 \\
Soil-fiber - drying & $2.39 \times 10^{-4}$ & 2.349 & 0.574 & 0.9726 \\
Soil-fiber - wetting & $2.20 \times 10^{-3}$ & 1.479 & 0.324 & 0.9701 \\
\hline
\end{tabular}

The curves have a very similar unimodal shape when evaluated within the same cycle. The Figure (3) shows the adjustment curves of 'pure soil' and 'soil-fiber' for both compiled trajectories, for better comparison. Farias et al. (2011) [25] point out that even with the increase in porosity caused by the increase of fibers in the clayey matrix, water retention is controlled by micropores, as the compaction carried out homogenizes the pores and reduces the macropores of the mixture. Thus, water retention should not be so influenced by the addition of fibers.

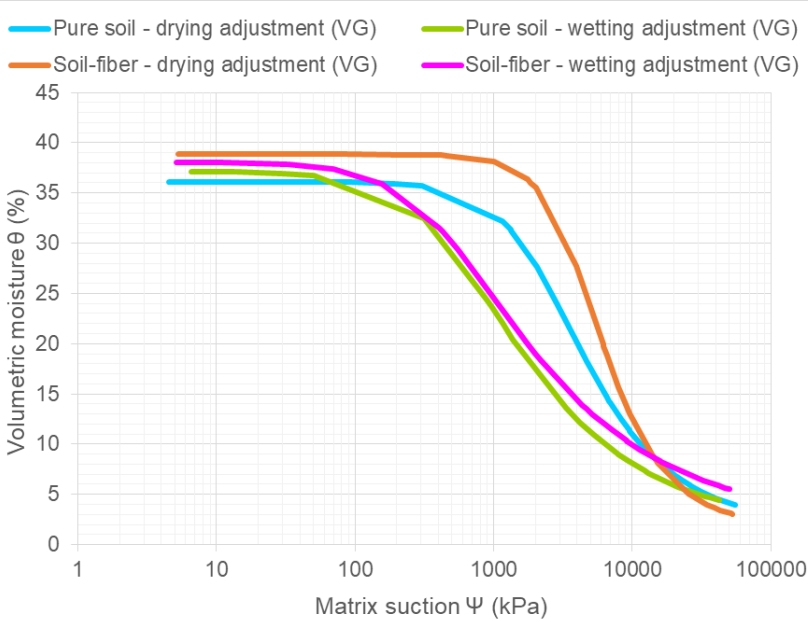

Fig. 3. Retention curves - van Genuchten's adjustments

It is possible to notice that the curves of the mixture are located above the curves of natural soil in both studied trajectories, indicating that the presence of fibers favored water retention for the same level of suction. Only for suctions greater than $15,000 \mathrm{kPa}$, in the drying cycle, the 'soil-fiber' curve exceeds the 'pure soil' curve, a region where the latter's retention would be higher. However, bearing in mind that Whatman filter paper $n^{\circ} 42$ is more susceptible to inaccuracies for suction values less than 10 $\mathrm{kPa}$ and greater than 29,000 kPa (Marinho 2005 [26]) in addition to the possibilities of operational error due to the rapid loss of moisture in the paper for the environment, the points located in the initial and final parts of the curve are more subject to variations.

The curves of the wetting cycle are practically parallel, with a difference of only $1 \%$ (of volumetric humidity) between them, approximately, with special proximity for suctions between 150 and $300 \mathrm{kPa}$. The adjustment curves are a bit more distant (about 2\% difference) for suctions greater than $4,000 \mathrm{kPa}$, but it is possible to notice that the experimental data obtained (points indicated in the graphs) are quite similar, so that it is concluded that for the wetting cycle the influence of fiber inclusion is less than in the drying cycle.

In addition, Oliveira (2004) [27] points out that it is common for there to be differences between the calibration curve of the method - in this case, by Chandler, Crilly \& Montgomery-Smith (1992) [22], and the batch of paper used, recommending the obtention of a calibration curve for each batch or verification of the validity of the calibration at some points on the curve, both procedures that were not performed and caused the need to discard points obtained that diverged greatly from the majority tendency to obtain adjustment curves with high determination coefficients. Thus, sections of very close curves do not allow a very precise analysis.

Both 'soil-fiber' curves showed an increase in saturation moisture, in relation to their corresponding 'pure soil' curve, even with small increases in the saturation stretch of the curves, which is the approximately constant interval before the air entry point. The increase of fiber to the soil increased the void index and provided a greater water storage capacity, as Oliveira Jr. (2018) [28] had already verified. Bearing in mind that the water retention curve is especially 
influenced by the structure of the compacted soil (Vanapalli, Fredlund \& Pufahl 1999 [29]), both the compaction moisture and the percentage of fiber addition are crucial to ensure soil-fiber adhesion and will also influence the hydraulic conductivity of the mixture.

The parameters obtained through the water retention curves are shown in Table (2). The 'pure soil' presented suction at the air entry point in the order of $900 \mathrm{kPa}$, while the 'soil-fiber', was in the order of $1,900 \mathrm{kPa}$. Oliveira Jr. (2018) [28] obtained values of 900 and $1,125 \mathrm{kPa}$, respectively, for the same 'pure soil' treated in this work and mixed with incorporation of the same percentage of fibers (1\%), with respective determination coefficients of 0.9847 and 0.9866 . This difference in values for the mixture may indicate that the soil-fiber adhesion in this case surpassed that occurred in the study of the aforementioned author.

Table 2. Parameters obtained through water retention curves

\begin{tabular}{l|cccc}
\hline Curve & $\begin{array}{c}\Psi \text { air entry } \\
(\mathrm{kPa})\end{array}$ & $\begin{array}{c}\theta \text { sat } \\
(\%)\end{array}$ & $\begin{array}{c}\theta \text { res } \\
(\%)\end{array}$ & $\begin{array}{c}\theta \mathrm{cc} \\
(\%)\end{array}$ \\
\hline Pure soil - drying & 900 & 36.10 & 1.68 & 36.09 \\
Pure soil - wetting & - & 37.11 & 1.53 & 36.94 \\
Soil-fiber - drying & 1,900 & 38.84 & 1.86 & 38.84 \\
Soil-fiber - wetting & - & 38.08 & 1.73 & 37.84 \\
\hline
\end{tabular}

It is worth noting that the fibers used in this work, although originating from the same productive group as Oliveira Jr. (2018) [28], come from different lots and are relatively spaced in time, which certainly brings variations in their properties, since coconut fiber is a material dependent on its cultivation, storage and collection conditions. Furthermore, the gravimetric distribution of the fibers used in this study differs greatly from that of that author: while only about $54 \%$ of the fibers were less than 5 cm long (19\% less than $1 \mathrm{~cm})$, more than $97 \%$ of Oliveira Jr.'s fibers [28] were smaller than $5 \mathrm{~cm}$ (approximately 16\% up to $1 \mathrm{~cm}$ ).

Although the pieces of fiber spare to the rings molded for the suction test were trimmed, longer fibers tend to be more gauge and have a larger surface area, which certainly influences their retention properties. The coincidence of the suction value of the air entry point for the 'pure soil' and the distance in the case of 'soil-fiber' demonstrate this situation, despite the fact that this interval of the graph is of rapid decline for both cases and there are points of 'soil-fiber' quite close to the 'pure soil' curve, which indicates that small variations in fiber properties can result in very different suction values at the air entry point.

The residual volumetric humidity was very similar for all the cases studied, with a slight increase in mixtures with fiber compared to natural soil in the same cycle (drying/ wetting), which, according to Rosário et al. (2011) [30], may be due to the predominantly polar surface energy of vegetal fibers and their greater affinity with water, which would increase retention. On the other hand, the increase in porosity caused by the addition of fibers facilitates the escape of water from voids, justifying the insignificant increase observed.
Field capacity humidity values $(\theta c c)$, estimated for a suction content of $33 \mathrm{kPa}$, were higher for fiber curves, both in the drying and wetting cycles, which directly reflects in the water storage capacity of the ground. These results demonstrate that the addition of coconut fibers in clayey soil favors greater retention and storage of water by the soil, both due to the polar properties of the fiber, and to the increase in the volume available for storage in view of the higher voids provided. The values found are consistent with the findings of Oliveira Jr. (2018) [28].

Such characteristics indicate that the increase of coconut fibers makes the soil more suitable for applications where it is subjected to drying and wetting cycles, such as covering layers of both landfills and contaminant containment barriers. The use of cover layers with greater water retention and storage capacity enables less percolation to be generated, since a higher percentage of rainwater will tend to be retained after infiltration, as well as reducing the emission of gases generated, since the increased layer moisture is responsible for reducing the permeability to air and gases - they are inversely related to unsaturated conditions.

\subsection{Unsaturated hydraulic conductivity}

The unsaturated hydraulic conductivity (to water) was estimated from the van Genuchten model [23] - Equations (7) and (8), using the parameters presented in Table (1) and average values of maximum hydraulic conductivity to water (saturated) obtained by Gusmão (2020) [31], which were 2.6 $\times 10^{-8} \mathrm{~m} / \mathrm{s}$ for the 'pure soil' curves, and $2.4 \times 10^{-8} \mathrm{~m} / \mathrm{s}$ for the 'soil-fiber' curves. The equations of unsaturated hydraulic conductivity for 'pure soil' in the drying and wetting paths are presented as Equations (12) and (13), respectively; and Equations (14) and (15) for 'soil-fiber', in that same order. The Figure (4) shows the curves adjusted from the mentioned equations.

$$
\begin{aligned}
& k\left(S_{\theta}\right)=2.6 \times 10^{-8} * S_{\theta}^{0.5}\left[1-\left(1-S_{\theta^{\frac{1.460}{0}}}\right)^{0.460}\right]^{2} \\
& k\left(S_{\theta}\right)=2.6 \times 10^{-8} * S_{\theta}^{0.5}\left[1-\left(1-S_{\theta^{\frac{1}{0.362}}}\right)^{0.362}\right]^{2} \\
& k\left(S_{\theta}\right)=2.4 \times 10^{-8} * S_{\theta}^{0.5}\left[1-\left(1-S_{\theta^{\frac{1}{0.574}}}\right)^{0.574}\right]^{2} \\
& k\left(S_{\theta}\right)=2.4 \times 10^{-8} * S_{\theta}{ }^{0.5}\left[1-\left(1-S_{\theta^{\frac{1}{0.324}}}\right)^{0.324}\right]^{2}
\end{aligned}
$$

The curves presented very similar tracings, and although the maximum values are very close $(\mathrm{S}=100 \%)$, there are clear differences in the rate of change in hydraulic conductivity with the change in the degree of saturation. It is interesting to note that the curves with fibers showed opposite behaviors: in the drying path they showed greater hydraulic conductivity to water in relation to the other curves, and in the wetting curve, less. In the drying path, the 'soil-fiber' showed a permeability variation in the range of $10^{-17}$ to $10^{-8} \mathrm{~m} / \mathrm{s}$, while in the wetting, from $10^{-23}$ to $10^{-8} \mathrm{~m} / \mathrm{s}$. The 'pure soil' remained in intermediate positions, varying 
between $10^{-20}$ and $10^{-8} \mathrm{~m} / \mathrm{s}$ in the drying path, and from $10^{-21}$ to $10^{-8} \mathrm{~m} / \mathrm{s}$ in the wetting.

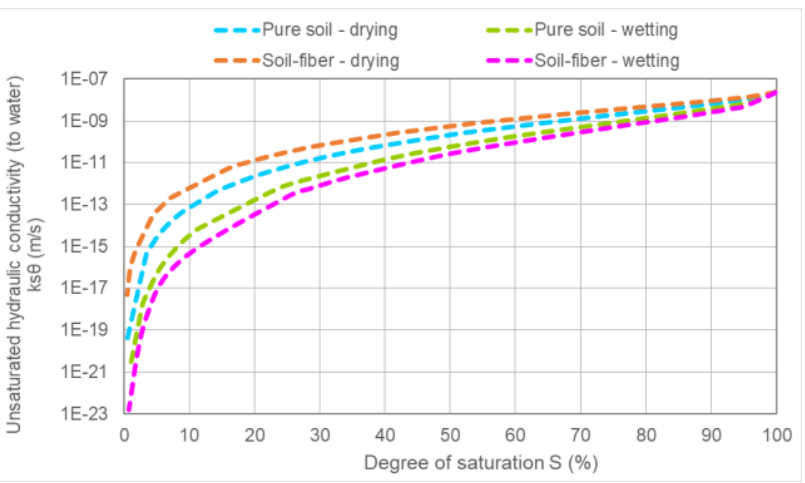

Fig. 4. Unsaturated hydraulic conductivity - van Genuchten model

These extremes behavior of the 'soil-fiber' demonstrates the effect of water retention of the fibers. It is known that the hydraulic conductivity to a given fluid grows with the increase of its presence in the environment due to the interconnections of paths that become available, and vice versa. In the drying cycle trajectory, starting from saturation, the greater capacity to retain the mixture promotes a slower water loss: it leaves more water available in the medium and facilitates its percolation between the voids. On the other hand, starting from the dry situation, the fibers' demand for water ends up prioritizing the proper incorporation of the water that is being made available, instead of filling the voids in the mixture, that is, the acquired water is not "free", which reduces the volume available for flow and hinders hydraulic conductivity.

Thus, the incorporation of fibers in the clayey soil promoted a change in the degree of saturation smoother both during drying and wetting. As mentioned, this feature is quite interesting for applications subject to wide variations in humidity, such as layers of landfill cover or vertical barriers to contain environmental contamination.

The van Genuchten model [23] also allowed, also using the parameters presented in Table (1), to estimate the variation of the relative permeability coefficient from soil to air - Equations (9) and (10) - and water - Equations (10) and (11) - depending on the degree of saturation, plotted together in Figure (5). The curves present similar traces, revealing a mirrored behavior in relation to air and water between the curves of the same type (pure soil/soil-fiber) and trajectory (drying/wetting). The formulas of the model itself already predict the mirroring, since one coefficient is the complementary from the other, considering that they are the only fluids present in the soil.

Observing the dashed curves of the theoretical models obtained, referring to the relative permeability of the soil to the air $(K r a)$, there is an indication that for dry soil up to a degree of saturation of almost $40 \%$, the flow of air is practically exclusive in the samples, with little possibility of water percolation. With the increase in humidity, there is a gradual increase in water permeability and a consequent decline in air permeability, with progressively increasing rates of variation. At about $90 \%$ saturation, a sudden change in the coefficients is noticed until reaching the extremes, especially for the section above $95 \%$.

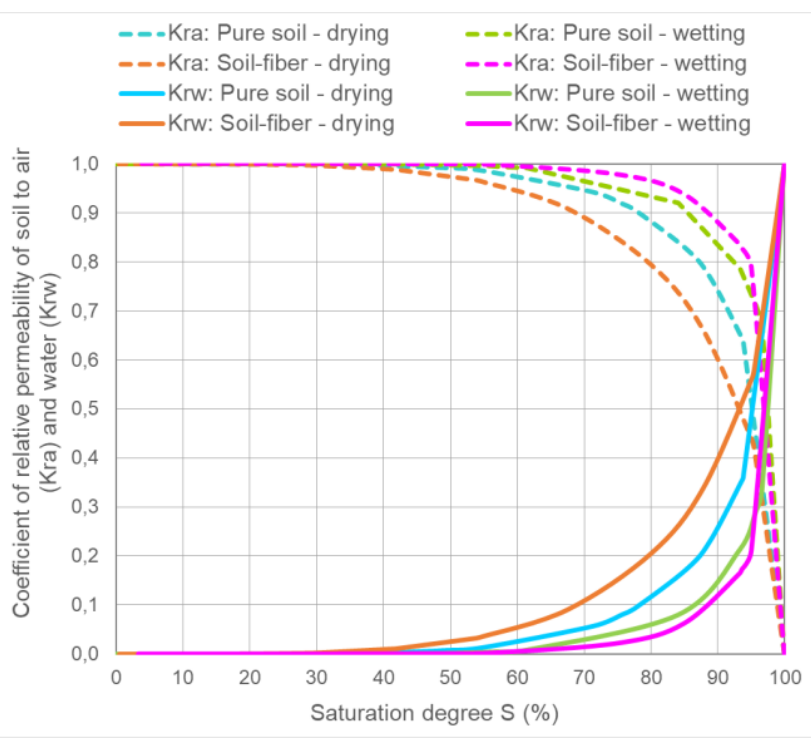

Fig. 5. Coefficient of relative permeability of soil to air $(\mathrm{Kra})$ and water $(K r w)$ as a function of the degree of saturation - van Genuchten's model

Although there is some differentiation in the strokes, it is possible to distinguish the general behavior of the curves in three parts. The first, for $\mathrm{S}<60 \%$, where the permeabilities are practically constant, with a little more noticeable variation in the 'soil-fiber' sample in the drying path. In the second interval, for $60 \%<\mathrm{S}<90 \%$, there is a slow decrease in air permeability and an increase in water permeability with increased saturation. And finally, for $\mathrm{S}>90 \%$, air and water permeability undergo drastic changes with small increments of water in the soil.

It is noteworthy that the curves obtained in this item came from theoretical adjustment models [23], with all the limitations that apply to it. Still, experimental investigations of the variation in air permeability as a function of the degree of saturation prove the estimate made (Loiseau, Cui \& Delage 2002 [18], Lopes 2011 [19], Maciel 2003 [17]; Maciel \& Jucá 2000 [16], Mariano 2008 [15]).

It is inferred that even a small reduction in the degree of saturation of an initially saturated soil is capable of causing major changes in the water permeability coefficient, which does not occur with air permeability in the case of a small increase in the degree of soil saturation initially dry. In a situation of low saturation, the incorporation of water by the soil is quite fast due to the high suction that exists, but the water cannot trace continuous paths that allow its movement and is retained next to the particles, in isolated points.

In the investigated models, a certain differentiation between the samples is perceived. The 'soil-fiber - drying' curves describe a reduction in permeability relative to air as of the degree of saturation of $40 \%$ and with a variation rate much higher than the other samples, which demonstrates a greater affinity with the water that favors the flow of water when it hinders the passage of air. However, the intersections between air and water permeability are very close for all samples: around 93\% saturation for 'soil-fiber drying'; 95\% for 'pure soil - drying'; 97\% for 'soil-fiber wetting'; and $98 \%$ for 'pure soil - wetting'. This indicates that although the 'soil-fiber - drying' sample has a greater variation along the intermediate degrees of saturation, the 
behavior of the four situations studied becomes very similar in the vicinity of saturation.

In any case, the higher the rate of variation of the Kra curves, the greater the affinity of the sample with water, which impairs air permeability in unsaturated conditions (and vice versa). The results are consistent with the unsaturated hydraulic (water) curves obtained (Figure 4), with the same order of presentation of the curves previously commented. On the other hand, comparing the relative permeabilities (Figure 5), it is found that the addition of fibers provides greater percolation of water along the drying path, while favoring the flow of air in the humidification - in relation to the natural soil. Pure soil has the same tendency for greater water retention in the drying cycle (than in wetting), but the addition of fibers has enhanced this characteristic.

During wetting, the air flow is able to maintain itself continuously until greater degrees of saturation and the relative air permeability suffers more sudden drops only in the vicinities of the saturation, when compared with the drying path. It is worth noting, however, that in wetting, the increase in fibers provided greater permeability relative to air only for $60 \%<\mathrm{S}<95 \%$ : for smaller values the air flows equally through both, and for larger ones, the fiber mixture maintains a greater permeability concerning water.

The van Genuchten [23] model provided an estimate of the unsaturated behavior of 'pure soil' and 'soil-fiber' mix as regards the flow of water and air, however, it is necessary to continue the studies to validate the theoretical estimates from empirical investigations and to prove the practical applications of the mixture. This type of evaluation is important for the definition of the degree of humidity that must be maintained in a covering layer so as to reduce the infiltration of rainwater as much as possible, so that it does not increase the volume of leachate generated, while preventing the escape of internal gases. produced in the decomposition of organic matter. It is also worth noting that other gases may behave differently from air, due to the lower or greater chemical and biological affinity that they may have with the soil and/or with coconut fibers.

\section{Final considerations}

The characteristic curves indicated that the addition of fibers increased the water retention of the soil to the same level of suction, especially in the drying trajectory, with an increase in the air entry point, field capacity humidity and water storage capacity. The polar properties of coconut fiber and the higher voids index provided by the addition of fibers in the soil (which increases the volume available for storage) justify this behavior.

The models of unsaturated hydraulic conductivity revealed the composite 'soil-fiber' tends to behave in extremes: in the drying path, the fibers increased the water permeability, and in the wetting path, they reduced it. In the same vein, the theoretical estimate of the relative permeability coefficients of the soil to air and to water as a function of the degree of saturation revealed that the addition of fibers provided greater water percolation in the drying path, and greater air flow during wetting, when compared to pure soil. This behavior reflects the greater retention capacity provided by the fibers, which promotes a more gradual change in the degree of saturation, in relation to the pure soil, what is a very interesting characteristic for applications subject to great variations in humidity.

\section{References}

1. M. F. Rosa, F. A. P. Abreu, A. A. L. Furtado, A. K. L. Brígido, E. R. V. Norões. (2001a). Processo agroindustrial: obtenção de pó de casca de coco verde. Comunicado Técnico 61. Fortaleza-CE, 4 p.

2. V. Silveira \& T. R. de P. Aragão. (2016). Viabilidade financeira de instalação de uma unidade de beneficiamento de cascas de coco verde. Rev. iPecege, 2:3, 72-85, 2016.

3. M. Ferreira Neto, H. R. Gheyi, J. S. de Holanda, J. F. de Medeiros, P. D. Fernandes. (2002). Qualidade do fruto verde de coqueiro em função da irrigação com água salina. Rev. bras. eng. agr. Amb. 6:1, 69-75.

4. G. O. Silva \& C. E. M. Jerônimo. (2012). Estudo de alternativas para o aproveitamento de resíduos sólidos da industrialização do coco. Rev. Monog. Amb. 10:10, 2193-2208.

5. A. P. Martins, T. Watanabe, P. L. R. Silva, C. Borelli, J. P. P. Marciano, R. A. Sanches. (2013). Aproveitamento de fibra de coco verde para aplicabilidade têxtil. Redige. 4:2, 111-116.

6. C. R. Martins \& L. A. de Jesus Jr. (2011). Evolução da produção de coco no Brasil e o comércio internacional: panorama 2010. Documentos 164. Aracaju: Embrapa Tabuleiros Costeiros.

7. M. F. Rosa, A. L. A. Mattos, L. A. Crisóstomo, M. C. B. De Figueiredo, F. C. Bezerra, L. G. Veras, D. Correia. (2009). Aproveitamento da casca de coco verde. In: J. M. M. De Carvalho (Org.). Apoio do BNB à pesquisa e desenvolvimento da fruticultura regional. Fortaleza: Banco do Nordeste do Brasil, 165-190.

8. H. Savastano Jr., L. L. Pimentel. (2000). Viabilidade do aproveitamento de resíduos de fibras vegetais para fins de obtenção de material de construção. Rev. Bras. de Eng. Agríc. Amb. 4:1, 103-110.

9. R. D. Toledo Filho, K. Ghavami, G. L. England, K. Scrivener. (2003). Development of vegetable fibremortar composites of improved durability. Cem. Conc. Comp. 25, 185-196.

10. S. B. Tamrakar, Y. Toyosawa, T. Mitachi, K. Itoh. (2005). Tensile strength of compacted and saturated soils using newly developed tensile strength measuring apparatus. Soils Found. 45:6, 103-110.

11. C.-S. Tang, D.-Y. Wang, B. Shi, J. Li. (2016) Effect of wetting-drying cycles on profile mechanical behavior of soils with different initial conditions. Catena. 139, 105116.

12. N. Shokri, P. Lehmann, P. Vontobel, D. Or. (2008). Drying front and water content dynamics during evaporation from sand delineated by neutron radiography. Water Ress. Resea. 44:W06418. 
13. D. G. Fredlund, H. Rahardjo, M. D. Fredlund. (2012). Unsaturated soil mechanics in engineering practice. New Jersey: John Wiley \& Sons, 926p.

14. F. A. M. Marinho. (1994). Medição de Sucção com o Método do Papel Filtro. In: Congresso Brasileiro De Mecânica Dos Solos E Engenharia De Fundações, 10, Foz do Iguaçu. Anais [...]. 515-522.

15. M. O. H. Mariano. (2008). Avaliação da retenção de gases em camadas de cobertura de aterros de resíduos sólidos. Thesis (Doctors in Civil Engineering) - Federal University of Pernambuco (UFPE), Recife/PE, Brazil.

16. F. J. Maciel \& J. F. T. Jucá. (2000). Laboratory and field tests for studying gas flow through MSW landfill cover soil. In: GEODENVER 2000, Denver (USA). Proceedings [...]. Denver: ASCE, 1-17.

17. F. J. Maciel. (2003). Estudo da geração, percolação e emissão de gases no aterro de resíduos sólidos da Muribeca/PE. Dissertation (Masters in Civil Engineering) - Federal University of Pernambuco (UFPE), Recife/PE, Brazil.

18. C. Loiseau, Y. J. Cui, \& P. Delage. (2002). Air conductivity of a heavily compacted swelling claysand mixture. In: International Conference On Unsaturated Soils - UNSAT, 3, Recife, 2002. Proceedings [...]. Lisse: Sweets \& Zeitlinger B. V. 1, 383-388.

19. R. L. Lopes. (2011). Infiltração de água e emissão de metano em camadas de cobertura de aterros de resíduos sólidos. Thesis (Doctors in Civil Engineering) - Federal University of Pernambuco (UFPE), Recife/PE, Brazil.

20. R. J. Chandler \& C. I. Gutierrez. (1986). The filter paper method of suction measurement. Geotechnique. 36, 265-268.

21. Associação Brasileira de Normas Técnicas (ABNT). (1988). NBR 7182: Solo - Ensaio de Compactação utilizando energia de compactação normal..

22. R. J. Chandler, M. S. Crilly \& G. Montgomery-Smith. (1992) A low-cost method of assessing clay desiccation for low-rise buildings. Proceedings of the Institute of Civil Engineers - Civil Engineering, 92:2, 82-89.

23. M. Th. van Genuchten. (1980). A closed form equation for predicting the hydraulic conductivity of unsatured soils. Proc. Soil. Soc. Am. 44:5, 892-898.

24. M. V. Ottoni. (2005) Classificação físico-hídrica de solos e determinação da capacidade de campo in situ a partir de testes de infiltração. Dissertation (Masters in Civil Engineering) - Federal University do Rio de Janeiro (UFRJ), Rio de Janeiro/RJ, Brazil.

25. W. M. Farias, J. Camapum De Carvalho, G. F. Silva, I. C. O. Campos, P. M. Santos Neto. (2011). Influência da Compactação nos Micro e Mesoporos Nanoestrurados e na Área Superficial Específica de um solo Laterítico. In: Simpósio Brasileiro De Solos Não Saturados, 7, 2011, Pirenópolis. Anais [...] Pirenópolis: Kelps. 1, 169-175.

26. F. A. M. Marinho. (2005). Os solos não saturados: aspectos teóricos, experimentais e aplicados. Text presented to the Polytechnic School of the University of São Paulo (USP) for the Free Teaching Competition in the specialty "Geomechanics" of the Department of
Structures and Foundations Engineering, São Paulo/SP, Brazil.

27. O. M. de Oliveira. (2004). Estudo sobre a resistência ao cisalhamento de um solo residual compactado não saturado. Thesis (Doctors in Engineering) - University of São Paulo (USP), São Paulo/SP, Brazil.

28. A. I. Oliveira Jr. (2018). Comportamento geotécnico de misturas compactadas de solo argiloso com fibras curtas de coco. Dissertation (Masters in Civil Engineering) Federal University of Pernambuco (UFPE), Recife/PE, Brazil.

29. S. K. Vanapalli, D. G. Fredlund \& D. E. Pufhal. (1999). The Influence of Soil Structure and Stress History on the Soil-Water Characteristics of a Compacted Till. Géotechnique. 49:2, 143-159.

30. F. Rosário, W. M. Pachekoski, A. P. J. Silveira, S. F. Dos Santos, H. Savastano Jr., S. A. Casarin. (2011). Resíduos de sisal como reforço em compósitos de polipropileno virgem e reciclado. Polímeros. 21, 90-97.

31. L. R. C. de Gusmão. (2020). Influência de ciclos secagem-molhagem no comportamento hidráulicomecânico de misturas compactadas de solo argiloso com fibras de coco verde. Dissertation (Masters in Civil Engineering) - Federal University of Pernambuco (UFPE), Recife/PE, Brazil. 